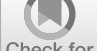

Check for

updates

Cite as

Nano-Micro Lett.

(2020) 12:180

Received: 13 May 2020

Accepted: 7 August 2020

Published online: 2 September 2020

(C) The Author(s) 2020

\section{Boosting Chemodynamic Therapy by the Synergistic Effect of Co-Catalyze and Photothermal Effect Triggered by the Second Near-Infrared Light}

\author{
Songtao Zhang ${ }^{1,2}$, Longhai Jin ${ }^{4}$, Jianhua Liu ${ }^{4}$, Yang Liu ${ }^{1}$, Tianqi Zhang ${ }^{4}$, Ying Zhao ${ }^{1}$, \\ $\mathrm{Na}$ Yin ${ }^{1}$, Rui Niu ${ }^{1}$, Xiaoqing $\mathrm{Li}^{1}$, Dongzhi Xue ${ }^{1}$, Shuyan Song ${ }^{1}$, Yinghui Wang ${ }^{1}{ }^{凶}$, \\ Hongjie Zhang ${ }^{1,2,3} \bowtie$ \\ $\square$ Yinghui Wang, yhwang@ciac.ac.cn; Hongjie Zhang, hongjie@ciac.ac.cn \\ 1 State Key Laboratory of Rare Earth Resource Utilization, Changchun Institute of Applied Chemistry \\ (CIAC), Chinese Academy of Sciences (CAS), Changchun 130022, People's Republic of China \\ 2 University of Chinese Academy of Sciences, Beijing 100049, People's Republic of China \\ 3 Department of Chemistry, Tsinghua University, Beijing 100084, People's Republic of China \\ 4 Department of Radiology, The Second Hospital of Jilin University, Changchun 130041, \\ People's Republic of China
}

\title{
HIGHLIGHTS
}

- The $\mathrm{MoS}_{2}$ nanosheets served as co-catalyst could reduce $\mathrm{Fe}^{3+}$ ions with lower Fenton reaction activity into the highly reactive Fe ${ }^{2+}$ ions, thereby boosting the production of hydroxyl radical $(\bullet \mathrm{OH})$ for high efficiency chemodynamic therapy $(\mathrm{CDT})$.

- The photothermal effect of $\mathrm{MoS}_{2}$ nanosheets motivated by second near-infrared light could further improve the treatment effectiveness by synergetic photothermal-enhanced CDT and photothermal therapy.

\begin{abstract}
In spite of the tumor microenvironments responsive cancer therapy based on Fenton reaction (i.e., chemodynamic therapy, CDT) has been attracted more attentions in recent years, the limited Fenton reaction efficiency is the important obstacle to further application in clinic. Herein, we synthesized novel $\mathrm{FeO} / \mathrm{MoS}_{2}$ nanocomposites modified by bovine serum albumin $\left(\mathrm{FeO} / \mathrm{MoS}_{2}\right.$-BSA) with boosted Fenton reaction efficiency by the synergistic effect of co-catalyze and photothermal effect of $\mathrm{MoS}_{2}$ nanosheets triggered by the second near-infrared (NIR II) light. In the tumor microenvironments, the $\mathrm{MoS}_{2}$ nanosheets not only can accelerate the conversion of $\mathrm{Fe}^{3+}$ ions to $\mathrm{Fe}^{2+}$ ions by $\mathrm{Mo}^{4+}$ ions on their surface to improve Fenton reaction efficiency, but also endow $\mathrm{FeO} / \mathrm{MoS}_{2}$-BSA with good photothermal performances for photothermal-enhanced CDT and photothermal therapy (PTT). Consequently, ben-
\end{abstract}

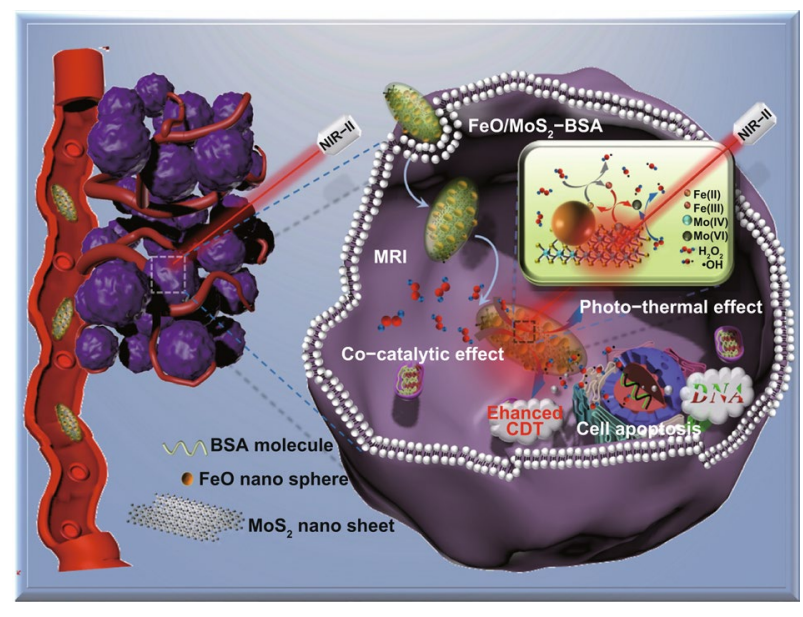
efiting from the synergetic-enhanced CDT/PTT, the tumors are eradicated completely in vivo. This work provides innovative synergistic strategy for constructing nanocomposites for highly efficient CDT.

KEYWORDS Chemodynamic therapy; Fenton reaction; Co-catalysis; Photothermal effect; NIR II biowindows 


\section{Introduction}

Nowadays, cancer is an illness which threatens the human health owing to its high mortality rate and recurrence rate $[1$, 2]. Several treatment strategies have been applied in clinic, such as surgery [3], radiotherapy [4], and chemotherapy [5, 6], but they still suffer from limited treatment effect and significant side effects. Recently, chemodynamic therapy (CDT) based on Fenton and Fenton-like reactions (denoted as generating highly oxidative hydroxyl radicals from hydrogen peroxide by ferrous or non-ferrous ions to remove organic pollutant) has drawn more attentions because it can generate the highly toxic reactive oxygen species [hydroxyl radicals $(\bullet \mathrm{OH})]$ in the tumor lesion area, resulting in high specificity and low side effects [7-13]. However, the weak acid and low transformation efficiency of $\mathrm{Fe}^{3+}$ to active $\mathrm{Fe}^{2+}$ in the tumor microenvironments lower the Fenton reaction efficacy, which leads to unsatisfactory therapy effect of CDT $[14,15]$. Therefore, it is urgent to develop new strategy to improve the Fenton reaction efficiency in the tumor microenvironments.

Recently, some promising strategies have been used to improve the treatment effect of CDT. For instance, $\mathrm{Bu}$ and coworker take advantage of photothermal effect to enhance the Fenton reactions efficiency, and obtain the good treatment effect of combinatorial CDT/PTT [7]. Our group has successfully utilized the light, ultrasound, and near-infrared II (NIR II) light-triggered photothermal effect to assist the Fenton reaction and improve the treatment effect. In addition to these methods that depend on the external stimulus to enhance the Fenton reactions efficiency [16, 17], the strategy that introduces a catalyst to accelerate the rate-controlling step of $\mathrm{Fe}^{3+} / \mathrm{Fe}^{2+}$ conversion has been attracted much more attentions recently in the field of treating persistent pollutants $[18,19]$. However, the research on improving the therapeutic efficacy of CDT with this co-catalytic strategy is rarely reported till now [20, 21]. If the catalyst also has good photothermal performance response to NIR II light for PTT, the improved therapeutic efficacy of CDT will be achieved through the synergistic effect.

Two-dimensional (2D) molybdenum disulfide $\left(\mathrm{MoS}_{2}\right)$ nanosheets have been used as photothermal agents owing to strong NIR absorbance and high photothermal conversion efficiency [22-25]. Meanwhile, $\mathrm{MoS}_{2}$ nanosheets have the peroxidase-mimic capability, making them catalyze decomposition of $\mathrm{H}_{2} \mathrm{O}_{2}$ to generate $\bullet \mathrm{OH}[10,26,27]$. Importantly, the active $\mathrm{Mo}^{4+}$ ions on the surface of $\mathrm{MoS}_{2}$ nanosheets can reduce $\mathrm{Fe}^{3+}$ ions into $\mathrm{Fe}^{2+}$ ions, accelerating the conversion of $\mathrm{Fe}^{3+}$ to $\mathrm{Fe}^{2+}$ [19]. Therefore, $\mathrm{MoS}_{2}$ nanosheets are good candidates to improve the therapeutic efficacy of CDT through the synergistic effect of photothermal effect/ co-catalysis.

Building from these ideas, herein, we design and synthesize novel $\mathrm{FeO} / \mathrm{MoS}_{2}$ nanocomposites modified by bovine serum albumin ( $\mathrm{FeO} / \mathrm{MoS}_{2}$-BSA) for magnetic resonance imaging guided highly efficient CDT (Scheme 1). $\mathrm{FeO} / \mathrm{MoS}_{2}$-BSA exhibits higher production efficiency of - $\mathrm{OH}$ compared to that of $\mathrm{FeO}$ and $\mathrm{MoS}_{2}$ individually, demonstrating that the co-catalysis strategy can improve the Fenton reaction efficacy. Moreover, owing to the absorption ability of $\mathrm{MoS}_{2}$ in NIR II region (1000-1350 nm), the photothermal (PT) effect of $\mathrm{FeO} / \mathrm{MoS}_{2}$-BSA triggered by NIR II light (1064 $\mathrm{nm})$ has been first employed to further improve the production efficiency of $\bullet \mathrm{OH}$. As the results, not only the cancer cells could be effectively killed by synergetic enhanced CDT and photothermal therapy (PTT), but also the tumors are eliminated completely in vivo experiments, indicating their highly efficient therapeutic efficiency in vitro and in vivo. In addition, the good magnetic properties of $\mathrm{FeO}$ endows $\mathrm{FeO} / \mathrm{MoS}_{2}$-BSA with great potential as contrast agents for MRI [28, 29]. This work thus presents a synergistic strategy of NIR II light motivate photothermal effect [30-33] and co-catalysis to construct nanotheranostic agents with high potency and low side effects.

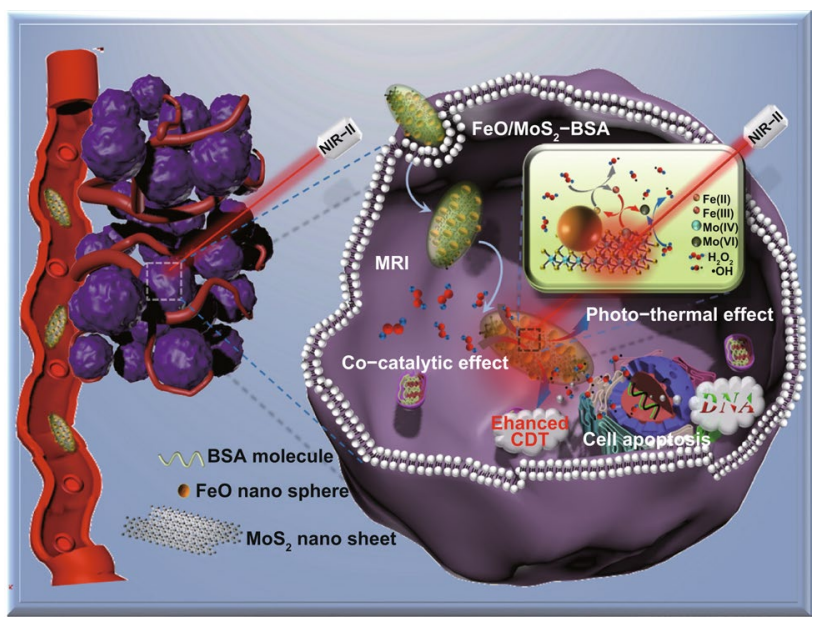

Scheme 1 Schematic presentation of $\mathrm{FeO} / \mathrm{MoS}_{2}$-BSA for MRI and synergetic enhanced CDT/PTT 


\section{Materials and Methods}

\subsection{Materials}

Ammonium molybdate, thiourea, NAC, iron(III) acetylacetonate $(99.9 \%)$, trioctylamine $(98 \%)$, oleic acid $(90 \%)$, nitrosonium tetrafluoroborate $\left(\mathrm{NOBF}_{4}\right)$, bovine serum albumin (BSA), p-phthalic acid (99\%) were purchased from Aladdin company. Calcein acetoxymethyl ester (Calcein AM), propidium iodide (PI), 2,7-dichlorofluorescin diacetate were obtained from Sigma-Aldrich (MO, USA). The CCK-8 was purchased from Changchun Sanbang Pharmaceutical Technology Co (Changchun, China). Other chemicals were purchased from Beijing Chemical Reagent Company.

\subsection{Preparation of $\mathrm{FeO} / \mathrm{MoS}_{2}$-BSA Nanocomposites}

\subsubsection{Preparation of $\mathrm{MoS}_{2}$ Nanosheets}

The large-scale $\mathrm{MoS}_{2}$ nanosheets were prepared following to the previous literature [23]: ammonium molybdate $(50 \mathrm{mg}$, $0.25 \mathrm{mmol}$ ) and NAC (50 mg, $0.3 \mathrm{mmol})$ were dissolved in ultrapure water $(30 \mathrm{~mL})$ in ice-water bath under stirring vigorously. Then, thiourea $(40 \mathrm{mg}, 0.5 \mathrm{mmol})$ was poured into the precursor solution under vigorous stirring for $30 \mathrm{~min}$. The mixture was added into a 40-mL Teflon-lined stainless steel autoclave at $200{ }^{\circ} \mathrm{C}$ for $8 \mathrm{~h}$. After cooling to room temperature, collected by centrifugation at $8000 \mathrm{r} \mathrm{min}^{-1}$ for $5 \mathrm{~min}$ and washed with water for three times. The small $\mathrm{MoS}_{2}$ nanosheets were obtained large-scale nanosheets under ultraphonic effect of ultrasonic cell disruptor for $1 \mathrm{~h}$, and then collect the upper suspension after centrifugation and re-dispersed in $10 \mathrm{~mL}$ water.

\subsubsection{Preparation of FeO Nanoparticles}

The FeO nanoparticles were synthesized by the thermal decomposition method [34]. The iron(III) acetylacetonate $(500 \mathrm{mg})$, oleic acid $(0.52 \mathrm{~mL})$, and trioctylamine $(20 \mathrm{~mL})$ were sequentially added into three-necked flask and heated at $150{ }^{\circ} \mathrm{C}$ for $30 \mathrm{~min}$ to remove water under argon gas protection, then slowly heated to $270{ }^{\circ} \mathrm{C}$ and kept for $10 \mathrm{~min}$ (rise rate: $2{ }^{\circ} \mathrm{C} \mathrm{min}^{-1}$ ). After cooling to room temperature,
FeO nanoparticles were collected by centrifugation at $8000 \mathrm{rpm}$ for $10 \mathrm{~min}$, and washed with cyclohexane and ethyl alcohol mixed solution for three times. The hydrophilic $\mathrm{FeO}$ nanoparticles were obtained by ligand-exchange strategy as follows [35]: $5 \mathrm{~mL}$ of $\mathrm{FeO}$ nanoparticles were dispersed in hexane $\left(\sim 5 \mathrm{mg} \mathrm{mL}^{-1}\right)$, and then $5 \mathrm{~mL}$ of dichloromethane solution of $\mathrm{NOBF}_{4}(0.01 \mathrm{M})$ was added into solution at room temperature under stirring vigorously for $10 \mathrm{~min}$. After that, the hydrophilic FeO nanoparticles were obtained by centrifugation at $2000 \mathrm{r} \mathrm{min}^{-1}$ for $5 \mathrm{~min}$ and washed with toluene and hexane (1:1 by volume) for two times.

\subsubsection{Preparation of FeO/MoS $\mathrm{MSA}_{2}$-Banocomposites}

The FeO nanoparticles solution ( $1 \mathrm{~mL}, 1000 \mathrm{ppm})$ was dropped into $10 \mathrm{~mL}$ of $\mathrm{MoS}_{2}$ nanosheets with mass concentration of Mo (200 ppm), respectively, under stirring vigorously for $20 \mathrm{~min}$, and then BSA solution $\left(1 \mathrm{~mL}, 5 \mathrm{mg} \mathrm{mL}^{-1}\right.$ ) was added into above mixed solution individually for $1 \mathrm{~h}$. The nanocomposites were collected by centrifugation at $8000 \mathrm{r} \mathrm{min}^{-1}$ for $10 \mathrm{~min}$ and washed with water for two times.

\subsection{Characterization}

Powder X-ray diffraction (XRD) was tested on a Bruker D8 Focus powder $\mathrm{X}$-ray diffraction with $\mathrm{Cu} \mathrm{K} \alpha$ radiation $(\lambda=1.5418 \AA)$ at $40 \mathrm{kV}$ and $40 \mathrm{~mA}$. Inductively coupled plasma (ICP) analyses were obtained from Varian Liberty 200 spectrophotometer to determine the contents. The UV-vis-NIR spectra were recorded on spectrometer (SHIMADZU, UV-3600). Infrared thermal imaging camera (FLIR T420, Fluke, USA). Transmission electron microscopic (TEM) images were obtained from a TECNAI G2 high resolution transmission electron microscope, operating at $200 \mathrm{kV}$. X-ray photoelectron spectroscopy (XPS) spectra were performed on an ESCALAB-MKII 250 photoelectron spectrometer (VG Co.) with $\mathrm{Al} \mathrm{K} \alpha \mathrm{X}$-ray radiation as the X-ray source for excitation. Discovery MR750w, GE, America. Bruker Avance III (9.4 T, $400 \mathrm{MHz}$ ) NMR spectrometer for magnetic resonance imaging. Fluorescence spectrometer (F-4800) for detection of PTA. 


\subsection{Detection of Extracellular $\bullet \mathrm{OH}$}

Series of sample solutions were prepared by adding different samples into total reaction volume of $2 \mathrm{~mL}$ PBS buffer solution (pH 6.0) containing $\mathrm{H}_{2} \mathrm{O}_{2}(0.5 \mathrm{mM})$ and PTA as fluorescence probe $\left(25 \mathrm{mg} \mathrm{L}^{-1}\right)$ for fluorescence intensity detection (EX: $315 \mathrm{~nm}$, EM: $425 \mathrm{~nm}$ ) with time. Samples are as follows: $\mathrm{FeO} / \mathrm{MoS}_{2}-\mathrm{BSA}, \mathrm{MoS}_{2}$ nanosheets, $\mathrm{FeO}$ nanoparticles.

\subsection{Photothermal Effect and Thermal Stability of $\mathrm{FeO} /$ $\mathrm{MoS}_{2}$-BSA Nanocomposites}

The temperature of $\mathrm{FeO} / \mathrm{MoS}_{2}$-BSA nanocomposites solution with different mass concentrations $(0,100,200$, and $400 \mu \mathrm{g} \mathrm{mL}^{-1}$ ) were measured by a thermocouple probe every minute for $10 \mathrm{~min}$ under the $1064 \mathrm{~nm}$ laser irradiation $\left(1.0 \mathrm{~W} \mathrm{~cm}^{-2}\right)$ and $808 \mathrm{~nm}$ laser irradiation $\left(0.3 \mathrm{~W} \mathrm{~cm}^{-2}\right)$. The temperature of $\mathrm{FeO} / \mathrm{MoS}_{2}$-BSA nanocomposites solution $\left(200 \mu \mathrm{g} \mathrm{mL}^{-1}\right)$ were measured by a thermocouple probe every minute for 10 min under the $1064 \mathrm{~nm}$ laser irradiation with different laser power $(0.3,0.5,0.75$, and $1.0 \mathrm{~W} \mathrm{~cm}^{-2}$ ). As for the thermal stability, the $\mathrm{FeO} / \mathrm{MoS}_{2}$ BSA nanocomposites solution $\left(200 \mu \mathrm{g} \mathrm{mL}^{-1}\right)$ was irradiated with $1064 \mathrm{~nm}$ laser $\left(0.75 \mathrm{~W} \mathrm{~cm}^{-2}\right)$ in quartz cuvette for 10 and $60 \mathrm{~min}$.

\subsection{MRI imaging Property}

The $T_{2}$-weighted MR imaging of $\mathrm{FeO} / \mathrm{MoS}_{2}$ - $\mathrm{BSA}$ nanocomposites with mole concentration ratio of $\mathrm{Fe}(0,0.03,0.06$, $0.12,0.25$, and $0.50 \mathrm{mM}$ ) were tested on the $3.0 \mathrm{~T}$ clinical scanner (Discovery MR750w, GE, America). The $T_{2}$ relaxation time of $\mathrm{FeO} / \mathrm{MoS}_{2}$-BSA nanocomposites solutions $\left(\mathrm{V}_{\mathrm{H}_{2} \mathrm{O}}: \mathrm{V}_{\mathrm{D}_{2} \mathrm{O}}=1: 1\right)$ with different mole concentrations of Fe was measured by Bruker Avance III (9.4 T, $400 \mathrm{MHz}$ ) NMR spectrometer.

\subsection{Cell Experiment}

\subsubsection{Cell Culture}

Human cervical adenocarcinoma epithelial cells (HeLa) were cultured with regular growth medium containing high glucose DMEM at $37{ }^{\circ} \mathrm{C}$ in a $5 \% \mathrm{CO}_{2}$ environment.
Cell culture media with different $\mathrm{pH}$ were adjusted by $\mathrm{HCl}$.

\subsubsection{Cytotoxicity Measurement of $\mathrm{FeO} / \mathrm{MoS}_{2}-\mathrm{BSA}$ Nanocomposites}

HeLa cells were seeded into 96-well plates for $24 \mathrm{~h}\left(37^{\circ} \mathrm{C}\right.$, $\left.5 \% \mathrm{CO}_{2}\right)$. Then, $\mathrm{FeO} / \mathrm{MoS}_{2}-\mathrm{BSA}$ nanocomposites $(0,50$, 100,200 , and $400 \mu \mathrm{g} \mathrm{mL}^{-1}$ ) were added into 96-well plates for $24 \mathrm{~h}$. Then, the HeLa cells were washed with PBS for 2 times. Then CCK-8 solution $(100 \mu \mathrm{L})$ was added and maintained for $3 \mathrm{~h}$. At last, the 96-well plates were putted into plate reader for analysis and the absorbance at $450 \mathrm{~nm}$ was recorded to measure the cell viability. Except for adding $\mathrm{H}_{2} \mathrm{O}_{2}$ and adjusting $\mathrm{pH}$ value of DMEM ( $\mathrm{pH}=6.5$ ), the other experiment is same as mentioned above for cytotoxicity measurement of $\mathrm{FeO} / \mathrm{MoS}_{2}$-BSA nanocomposites in stimulated TME.

\subsubsection{In Vitro Photothermal-assisted CDT of FeO/ $\mathrm{MoS}_{2}$-BSA Nanocomposites}

HeLa cells were seeded in 96-well plates for $24 \mathrm{~h}$. Then, $\mathrm{FeO} /$ $\mathrm{MoS}_{2}$-BSA nanocomposites solution $(0,50,100,200$, and $400 \mu \mathrm{g} \mathrm{mL}^{-1}$ ) were added into the HeLa cells containing $\mathrm{H}_{2} \mathrm{O}_{2}$ $(0.01 \mathrm{mM})$ for $24 \mathrm{~h}$. Then, the HeLa cells were irradiated with $1064 \mathrm{~nm}$ laser $\left(0.75 \mathrm{~W} \mathrm{~cm}^{-2}\right)$ for $10 \mathrm{~min}$. After that, the HeLa cells were washed with PBS for 2 times and incubated with CCK-8 solution $(100 \mu \mathrm{L})$ for $3 \mathrm{~h}$. At last, the 96 -well plates were putted into plate reader for analysis and the absorbance at $450 \mathrm{~nm}$ was recorded to measure the cell viability.

\subsubsection{Detection of Intracellular $\cdot \mathrm{OH}$ by $\mathrm{DCFH}-\mathrm{DA}$}

HeLa cells were seeded in six-well plate containing $\mathrm{H}_{2} \mathrm{O}_{2}$ for $12 \mathrm{~h}$. $\mathrm{FeO} / \mathrm{MoS}_{2}-\mathrm{BSA}$ with mass concentration of $200 \mu \mathrm{g} \mathrm{mL}^{-1}$ were added into and incubated for $4 \mathrm{~h}$. After incubating with DCFH-DA $(10 \mu \mathrm{M})$ with or without $1064 \mathrm{~nm}$ laser irradiation $\left(0.75 \mathrm{~W} \mathrm{~cm}^{-2}\right)$ for $5 \mathrm{~min}$ and after washing with PBS for two times, the fluorescence imaging of cells were monitored by confocal microscopy. 


\subsubsection{PI/AM Co-staining}

HeLa cells were seeded in six-well plate for $12 \mathrm{~h}$. FeO/ $\mathrm{MoS}_{2}$-BSA with mass concentration of $200 \mu \mathrm{g} \mathrm{mL}^{-1}$ in DMEM containing $\mathrm{H}_{2} \mathrm{O}_{2}$ were added and incubated for $4 \mathrm{~h}$. Then, cells were irradiated with or without $1064 \mathrm{~nm}$ laser $\left(0.75 \mathrm{~W} \mathrm{~cm}^{-2}\right)$ for $10 \mathrm{~min}$. After washing with PBS for two times and co-stained with calcein $\mathrm{AM}$ and propidium iodide (PI) for $30 \mathrm{~min}$. After washing with PBS for two times, the cellular modality of cells was monitored by fluorescence microscopy.

\subsection{Animal Experiment}

All of the animal experiments were carried out under the NIH guidelines for the care and use of laboratory animals (NIH Publication No. 85-23 Rev. 1985) and approved by the Jilin University Animal Care and Use Committee. Kunming mices ( $20 \mathrm{~g}$ ) were purchased from Laboratory Animal Center of Jilin University (Changchun, China).

\subsubsection{In Vivo Therapy}

The U14 cells were subcutaneously injected into the underarm of Kunming mice. Thirty mice bearing U14 tumor $\left(\approx 120 \mathrm{~mm}^{3}\right)$ were randomly allocated into four groups: (a) control group, (b) laser group, (c) $\mathrm{FeO} / \mathrm{MoS}_{2}$-BSA nanocomposites group, (d) $\mathrm{FeO} / \mathrm{MoS}_{2}$-BSA nanocomposites + laser group. The mice in the (b) and (d) group were irradiated under the $1064 \mathrm{~nm}$ laser for $10 \mathrm{~min}$ with $0.75 \mathrm{~W} \mathrm{~cm}^{-2}$ laser power after tail intravenous injection with equal volume of physiological saline $(200 \mu \mathrm{L})$ and $\mathrm{FeO} / \mathrm{MoS}_{2}$-BSA nanocomposites $\left(200 \mu \mathrm{L}, 400 \mu \mathrm{g} \mathrm{mL}{ }^{-1}\right)$, respectively. The same procedure was applied in c) and d) group with exception of no laser irradiation. The treatment procedure with or without $1064 \mathrm{~nm}$ laser irradiation was repeated four times in four days, the electronic balance and digital calipers were used to measure the body weight and tumor size every 2 days. The tumor volume was calculated by the equation $($ Volume $=($ Tumor Length $) \times($ Tumor Width $)^{2} / 2$ ). The tumors were dissected out and photographed to evaluate the therapeutic effect after 2 weeks.

\subsubsection{In Vivo $M R I$}

The $T_{2}$-weighted MRI of tumor bearing mice were conducted by using $3.0 \mathrm{~T}$ clinical scanner (Discovery MR750w, GE, America) after tail intravenous injection with $\mathrm{FeO} /$ $\mathrm{MoS}_{2}$-BSA nanocomposites $\left(200 \mu \mathrm{L}, 400 \mu \mathrm{g} \mathrm{m}^{-1}\right)$ for 0 , 4,12 , and $24 \mathrm{~h}$. The $T_{2}$-weighted imaging was disposed with the following optimal parameters of instrument $(\mathrm{TE}=104.6 \mathrm{~ms}, \mathrm{TR}=3000 \mathrm{~ms}, \mathrm{FOV}=200 \times 200 \mathrm{~mm})$.

\subsubsection{Biodistribution of $\mathrm{FeO} / \mathrm{MoS}_{2}$-BSA Nanocomposites}

The tumor-bearing mice were necked off after intravenously injected with $\mathrm{FeO} / \mathrm{MoS}_{2}$-BSA nanocomposites solution (400 $\mu \mathrm{g} \mathrm{mL}^{-1}, 200 \mu \mathrm{L}$ ) for 1,7 , and $14 \mathrm{~d}$. Then, the heart, liver, spleen, lungs, kidneys, and tumors of mice were dissected out. After recording the weight of every tissues, $5 \mathrm{~mL}$ of digesting aquaregia $\left(\mathrm{HNO}_{3}: \mathrm{HCl}=1: 3\right)$ was added for $48 \mathrm{~h}$. The content of Mo was measured by ICP-AES.

\subsubsection{TUNEL and H\&E Staining}

The tumor-bearing mice were killed on the third day, the tumor tissues were dissected out for hematoxylin and eosin (H\&E) staining and TdT-mediated dUTP nick end labeling (TUNEL). Tumor-bearing mice were necked off on the 14th day, and the heart, liver, spleen, lung, kidney were dissected out and immersed in formalin and processed in paraffin for H\&E staining.

\section{Results and Discussion}

\subsection{Characterization of $\mathrm{FeO} / \mathrm{MoS}_{2}-\mathrm{BSA}$ Nanocomposites}

The $\mathrm{MoS}_{2}$ nanosheets with average size of $150 \mathrm{~nm}$ were obtained after sonicating the solution of large $\mathrm{MoS}_{2}$ sheets $(>1 \mu \mathrm{m})$ which is shown in Fig. 1a, b, and as shown in Fig. S1a, the X-ray diffraction (XRD) pattern can be indexed well to $2 \mathrm{H}-\mathrm{MoS}_{2}$ phase (JCPDS No. 37-1492). The ligand-free $\mathrm{FeO}$ nanospheres were synthesized following the previous report [34], and the average diameter was determined to be $8 \pm 3 \mathrm{~nm}$ by transmission electron microscopy which is (TEM) shown in Figs. 1c and S2. The high resolution TEM image in the inner picture of Fig. 1c shows that the lattice 

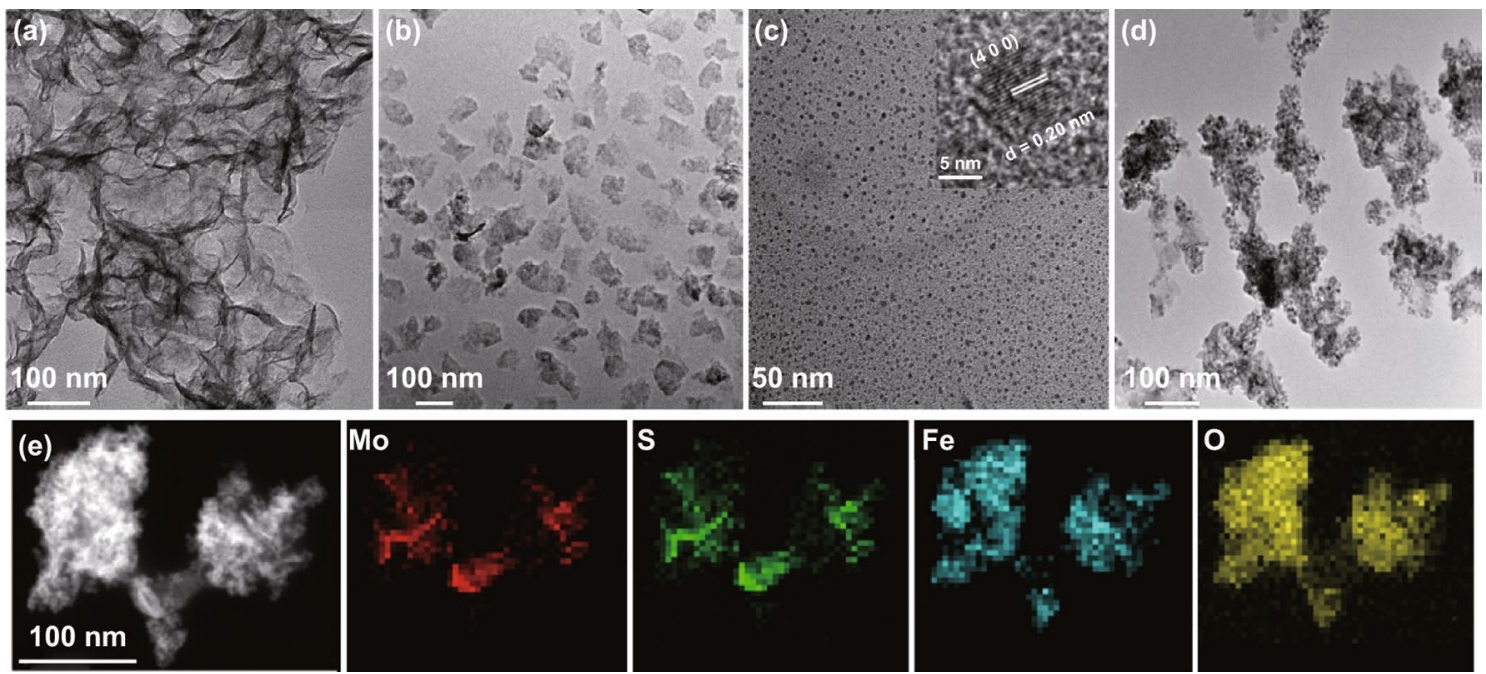

Fig. 1 Characterization of $\mathrm{FeO} / \mathrm{MoS}_{2}$-BSA nanocomposites. a, b TEM images of large and small $\mathrm{MoS}_{2}$ nanosheets. c, $\mathbf{d}$ TEM images of FeO nanoparticles and $\mathrm{FeO} / \mathrm{MoS}_{2}-\mathrm{BSA}$ nanocomposites, and inset in c HRTEM image of FeO nanoparticle. e STEM image and EDS elemental mapping of $\mathrm{FeO} / \mathrm{MoS}_{2}-\mathrm{BSA}$ nanocomposites

fringes with d-spacing of $0.20 \mathrm{~nm}$ corresponds to the $(400)$ plane of $\mathrm{FeO}$, which is consistent with the $\mathrm{FeO}$ (JCPDS No. 19-0629, Fig. S1b). Afterward, $\mathrm{FeO} / \mathrm{MoS}_{2}$ nanocomposites were obtained by electrostatic interaction, and modified by bovine serum albumin (BSA) to improve their biocompatibility (Fig. S3). The TEM image in Fig. 1d illustrates that $\mathrm{FeO}$ nanospheres were successfully anchored on the surface of $\mathrm{MoS}_{2}$ nanosheets. The energy dispersive X-ray (EDX) mappings shown in Fig. 1e confirm the chemical composition of $\mathrm{FeO} / \mathrm{MoS}_{2}-\mathrm{BSA}$ nanocomposites. The characteristic diffractions of $\mathrm{FeO}$ and $\mathrm{MoS}_{2}$ can be indexed in XRD pattern and selected area electron diffraction (SAED) of $\mathrm{FeO} /$ $\mathrm{MoS}_{2}$-BSA nanocomposites (Figs. S1c and S4), further demonstrating the successful synthesis of $\mathrm{FeO} / \mathrm{MoS}_{2}$-BSA nanocomposites. The X-ray photoelectron spectroscopy (XPS) analysis provides more information of the composition and surface electronic states of $\mathrm{FeO} / \mathrm{MoS}_{2}-\mathrm{BSA}$ nanocomposites (Fig. S5). The high-resolution Fe 2p spectrum shows two peaks at 710.5 and $724.3 \mathrm{eV}$, which were attributed to $\mathrm{Fe}^{2+}$. The peaks at 228, 232, and $225 \mathrm{eV}$ correspond to the data reported for Mo $3 \mathrm{~d}_{5 / 2}\left(\mathrm{Mo}^{4+}\right)$, Mo $3 \mathrm{~d}_{3 / 2}\left(\mathrm{Mo}^{4+}\right)$, and S $2 \mathrm{~s}$, and two peaks at 161 and $162 \mathrm{eV}$ represent the $2 \mathrm{p}_{3 / 2}$ and $2 \mathrm{p}_{1 / 2}$ of $\mathrm{S}^{2-}$, revealing the existence of $\mathrm{MoS}_{2}$ in the nanocomposites [23]. The presence of the peaks of N 1s and C 1s confirms the successful modification BSA on the surface of $\mathrm{FeO} / \mathrm{MoS}_{2}$. The Fourier transform infrared spectroscopy (FT-IR) results further evidence the successful BSA functionalization (Fig. S6). The hydrodynamic diameters of $\mathrm{FeO} / \mathrm{MoS}_{2}$-BSA nanocomposites in normal saline and PBS solution are 227.1 and $246.0 \mathrm{~nm}$ with low PDI value, respectively, indicating their good dispersity and stability in physiological environments (Fig. S7, Table S1).

\subsection{Synergetic Enhanced CDT/PTT of $\mathrm{FeO} / \mathrm{MoS}_{2}-\mathrm{BSA}$ in vitro}

To evaluate the $\bullet \mathrm{OH}$ production capacity of $\mathrm{FeO} / \mathrm{MoS}_{2}-\mathrm{BSA}$ nanocomposites, p-phthalic acid (PTA) was choosed as fluorescence probe to monitor the $\bullet \mathrm{OH}$ production in phosphate buffer solution (PBS) with $\mathrm{pH}$ value of 6.0, whose fluorescence emission at $425 \mathrm{~nm}$ enhanced as the increasing of the amount of $\bullet \mathrm{OH}$. As shown in Fig. 2a, the $\bullet \mathrm{OH}$ production ability of $\mathrm{FeO} / \mathrm{MoS}_{2}$-BSA is not only higher than that of $\mathrm{FeO}$ and $\mathrm{MoS}_{2}$ separately, but also the total amount of them ( $\mathrm{FeO}$ $+\mathrm{MoS}_{2}$ ), indicating that the co-catalyst $\mathrm{MoS}_{2}$ can actually improve the generation efficiency of $\bullet \mathrm{OH}$. This result maybe can ascribe to the fact that the active $\mathrm{Mo}^{4+}$ ions on the surface of $\mathrm{MoS}_{2}$ nanosheets can reduce $\mathrm{Fe}^{3+}$ ions into $\mathrm{Fe}^{2+}$ ions, accelerating the conversion of $\mathrm{Fe}^{3+}$ to active $\mathrm{Fe}^{2+}$.

Moreover, $\mathrm{FeO} / \mathrm{MoS}_{2}$-BSA nanocomposites exhibit stronger absorption at 808 and $1064 \mathrm{~nm}$ than that of $\mathrm{FeO}$, indicating $\mathrm{MoS}_{2}$ nanosheets endow them with good photothermal property (Fig. S8). Then, we compared the photothermal effects of different concentrations of $\mathrm{FeO} / \mathrm{MoS}_{2}-$ BSA nanocomposites exposed to 808 and $1064 \mathrm{~nm}$ laser 

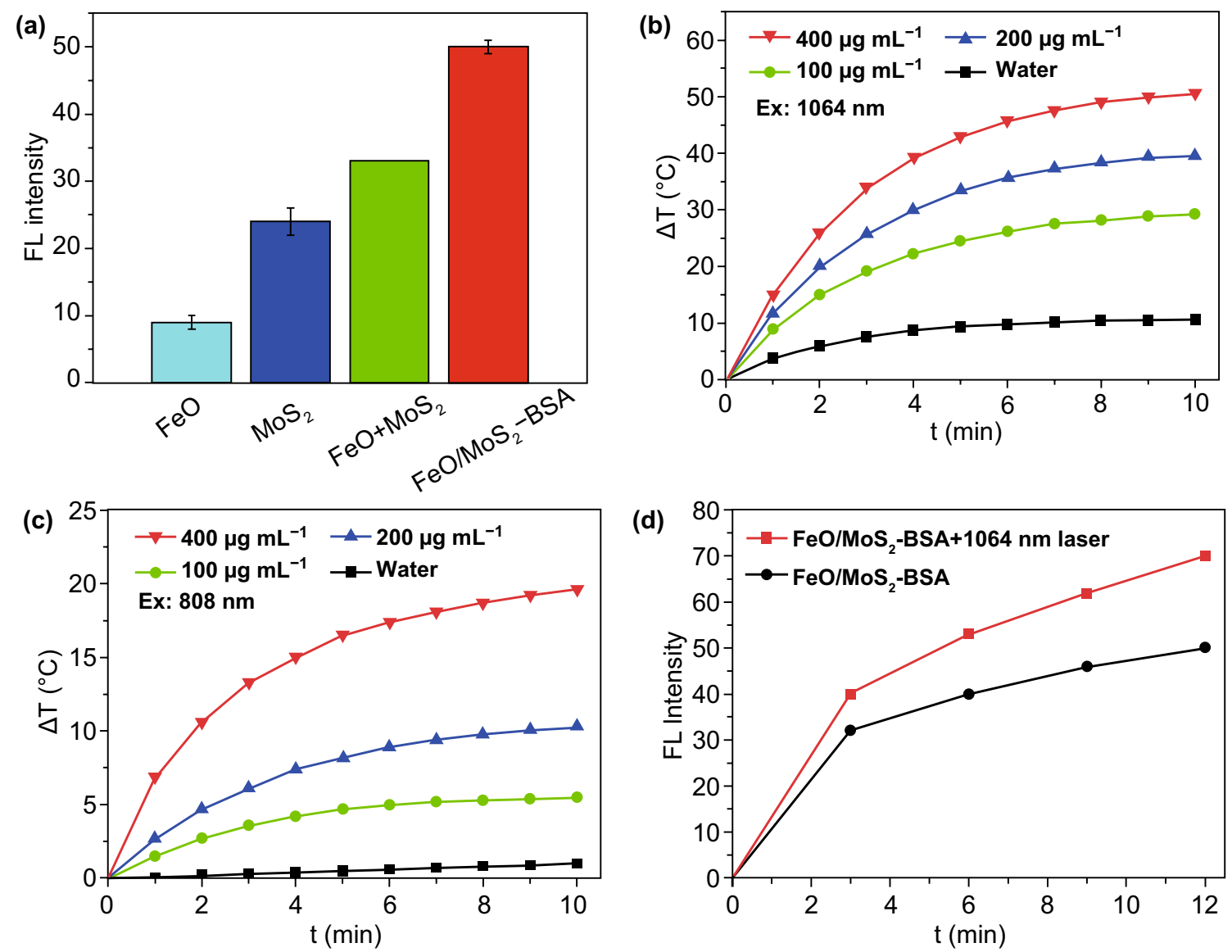

Fig. 2 a $\bullet \mathrm{OH}$ production capacity of $\mathrm{FeO}, \mathrm{MoS}_{2}, \mathrm{MoS}_{2}+\mathrm{FeO}$, and $\mathrm{FeO} / \mathrm{MoS}_{2}$-BSA solutions mixed with $\mathrm{H}_{2} \mathrm{O}_{2}$. b, c Temperature curves of different concentration $\mathrm{FeO} / \mathrm{MoS}_{2}$-BSA under irradiation with $1064 \mathrm{~nm}$ and $808 \mathrm{~nm}$ laser $\left(1\right.$ and $0.3 \mathrm{~W} \mathrm{~cm}^{-2}$ separately). d PT-enhanced $\bullet \mathrm{OH}$ generation of $\mathrm{FeO} / \mathrm{MoS}_{2}-\mathrm{BSA}$ nanocomposites with or without $1064 \mathrm{~nm}$ laser irradiation $\left(0.75 \mathrm{~W} \mathrm{~cm}^{-2}\right)$

with maximum permissible exposure (MPE, $0.3 \mathrm{~W} \mathrm{~cm}^{-2}$ for $808 \mathrm{~nm}$ and $1 \mathrm{~W} \mathrm{~cm}^{-2}$ for $1064 \mathrm{~nm}$ ), respectively. As shown in Fig. 2b, c, the temperature of $\mathrm{FeO} / \mathrm{MoS}_{2}-\mathrm{BSA}$ nanocomposites $\left(200 \mu \mathrm{g} \mathrm{mL}^{-1}\right)$ could increase to $57{ }^{\circ} \mathrm{C}$ after irradiation with $1064 \mathrm{~nm}$ laser for $10 \mathrm{~min}$. In contrast, it just reaches to $30^{\circ} \mathrm{C}$ under illumination with $808 \mathrm{~nm}$ laser in the same conditions. In fact, even irradiation with $1064 \mathrm{~nm}$ laser at $0.75 \mathrm{~W} \mathrm{~cm}^{-2}$ (lower than MPE: $1 \mathrm{~W} \mathrm{~cm}^{-2}$ ), $\mathrm{FeO}$ / $\mathrm{MoS}_{2}$-BSA nanocomposites show good photothermal performances (Fig. S9). The photothermal conversion efficiency was calculated to be $56 \%$ for $1064 \mathrm{~nm}$ (Figs. S10 and S11), demonstrating the outstanding photothermal performance of $\mathrm{FeO} / \mathrm{MoS}_{2}$-BSA nanocomposites responsive to NIR II light. As shown in Fig. S12, there is no absorption decrease in $\mathrm{FeO} / \mathrm{MoS}_{2}-\mathrm{BSA}$ after irradiation for $1 \mathrm{~h}$, revealing that the $\mathrm{FeO} / \mathrm{MoS}_{2}$-BSA possess good photothermal stability. Importantly, the $\bullet \mathrm{OH}$ production capacity of $\mathrm{FeO} / \mathrm{MoS}_{2}$-BSA nanocomposites was effectively enhanced after irradiation with $1064 \mathrm{~nm}$ laser for $12 \mathrm{~min}$ (Figs. 2d and S13), which indicates that the photothermal effect of $\mathrm{FeO} / \mathrm{MoS}_{2}-\mathrm{BSA}$ nanocomposites triggered by NIR II light could not only cause cancer cells death for PTT, but also achieve highly efficient CDT.

For further application in vivo, the potential cytotoxicity of $\mathrm{FeO} / \mathrm{MoS}_{2}$-BSA nanocomposites was evaluated by a standard Cell Counting Kit-8 (CCk-8) assay. As shown in Fig. 3a, after incubated with different concentrations of $\mathrm{FeO} / \mathrm{MoS}_{2}$-BSA nanocomposites for $24 \mathrm{~h}$, no significant cytotoxicity for HeLa cells was observed, showing their good biocompatibility (Fig. S14). However, the cell viability decreased with the concentration increase in $\mathrm{FeO}$ / $\mathrm{MoS}_{2}$-BSA nanocomposites under stimulated tumor microenvironments ( $100 \mu \mathrm{M} \mathrm{H}_{2} \mathrm{O}_{2}$ ), which could be attributed to the DNA damage of HeLa cells caused by $\bullet \mathrm{OH}$ production 
(a)

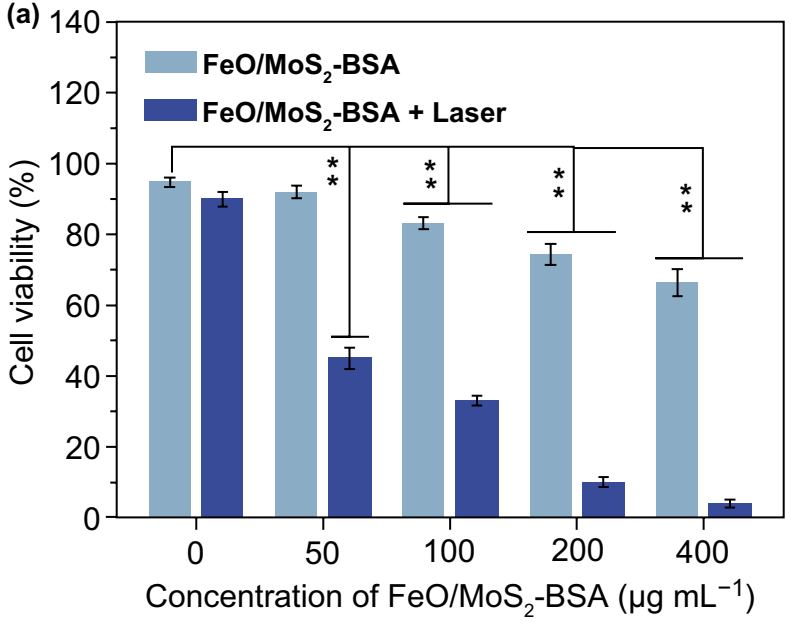

(b)

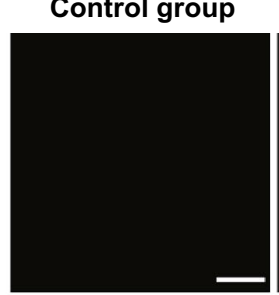

$\mathrm{FeO} / \mathrm{MoS}_{2}$-BSA

group

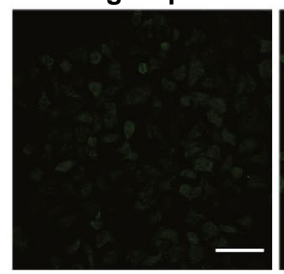

Laser group

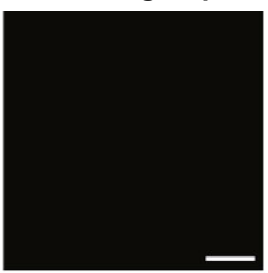

$\mathrm{FeO} / \mathrm{MoS}_{2}$-BSA + laser group

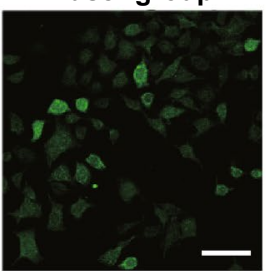

(c)

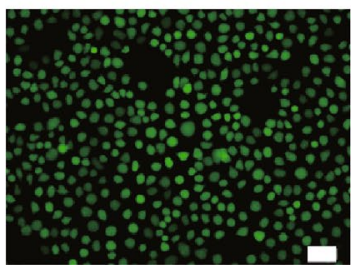

Control group

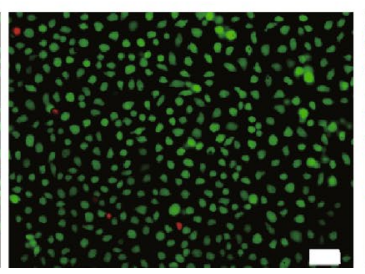

Laser group

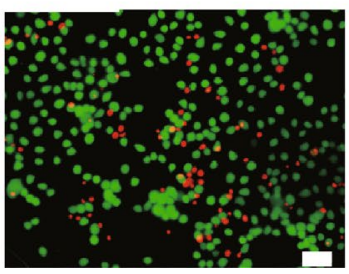

$\mathrm{FeO} / \mathrm{MoS}_{2}$-BSA group

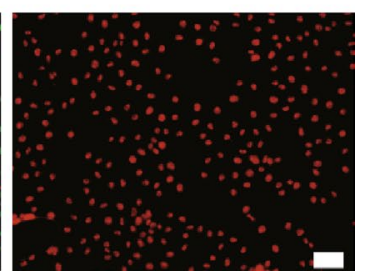

$\mathrm{FeO} / \mathrm{MoS}_{2}-\mathrm{BSA}+$ laser group

Fig. 3 a Cell viability of Hela cells with different treatments (Data are means $\pm \mathrm{SD} ; N=3$ ). b Confocal fluorescence images of Hela cells treated with $\mathrm{FeO} / \mathrm{MoS}_{2}$-BSA nanocomposites and DCFH-DA with or without $1064 \mathrm{~nm}$ irradiation $\left(0.75 \mathrm{~W} \mathrm{~cm}^{-2}\right)$. c fluorescence images of Hela cells co-stained with Calcein AM and PI after various treatments $(* * P<0.01)$. Scale bar: $50 \mu \mathrm{m}$

through Fenton reaction. After irradiation with $1064 \mathrm{~nm}$ laser for $10 \mathrm{~min}$, the cell viability is no more than $10 \%$, showing the highly efficient antitumor efficacy of combinatorial PTT and PT-enhanced CDT. To confirm the generation of active $\bullet \mathrm{OH}$ in cells, 2,7-dichlorofluorescein diacetate (DCFH-DA) was used as fluorescence probe for tracking ROS production, which produces green fluorescence triggered by $\bullet \mathrm{OH}$. As shown in Fig. 3b, compared to the control and laser groups, the weak green emission was observed after treated with $\mathrm{FeO} / \mathrm{MoS}_{2}$-BSA nanocomposites, demonstrating the generation $\bullet \mathrm{OH}$ in $\mathrm{HeLa}$ cells by $\mathrm{Fe}^{2+}$ and overpressed $\mathrm{H}_{2} \mathrm{O}_{2}$ through Fenton reaction. Moreover, $\mathrm{FeO} / \mathrm{MoS}_{2}$-BSA+ $1064 \mathrm{~nm}$ laser group shows obviously enhanced green fluorescence, indicating that the photothermal effects of $\mathrm{FeO} / \mathrm{MoS}_{2}$-BSA nanocomposites triggered by NIR II laser illumination can significantly improve the generation efficiency of $\bullet \mathrm{OH}$. The good treatment effect of $\mathrm{FeO} / \mathrm{MoS}_{2}$-BSA nanocomposites on HeLa cells was further proved by calcein AM and propidium iodide (PI) staining. As shown in Fig. 3c, the control and laser groups show the strong green fluorescence (live cells) and ignorable red fluorescence (dead cells), but the $\mathrm{FeO} / \mathrm{MoS}_{2}$-BSA nanocomposites group shows enhanced red fluorescence, indicating the destruction of HeLa cells by $\bullet \mathrm{OH}$. The stronger red fluorescence was observed after irradiation with $1064 \mathrm{~nm}$ laser for $10 \mathrm{~min}$, revealing the good antitumor effect of $\mathrm{FeO} /$ $\mathrm{MoS}_{2}$-BSA nanocomposites by PTT and PT-enhanced CDT. All these results show that $\mathrm{FeO} / \mathrm{MoS}_{2}$-BSA nanocomposites have good potential for effective PT-enhanced CDT/PTT synergistic therapy.

\subsection{Synergetic Enhanced CDT/PTT Effect of FeO/ MoS $_{2}-$ BSA in vivo}

Encouraged by the good antitumor effect in vitro, we further investigated the tumor inhibiting efficacy of $\mathrm{FeO} / \mathrm{MoS}_{2}-\mathrm{BSA}$ nanocomposites on U14 tumor xenograft model. The photothermal performances of $\mathrm{FeO} / \mathrm{MoS}_{2}$-BSA nanocomposites in vivo were confirmed by IR thermal camera. As shown in Figs. 4a and S15, compared to the control group, the temperature of tumor site rapidly increased to $52{ }^{\circ} \mathrm{C}$ under 
the $1064 \mathrm{~nm}$ laser irradiation for $10 \mathrm{~min}$ after intravenous injection with $\mathrm{FeO} / \mathrm{MoS}_{2}$-BSA nanocomposites, demonstrating that $\mathrm{FeO} / \mathrm{MoS}_{2}$-BSA nanocomposites could be served as good photothermal agent responsive to the NIR II light for achieving highly efficient PTT and promoting Fenton reaction efficiency. Then, the mice bearing tumor were randomized into four groups: (a) control group, (b) laser group, (c) $\mathrm{FeO} / \mathrm{MoS}_{2}$-BSA nanocomposites group, and (d) $\mathrm{FeO} / \mathrm{MoS}_{2}$-BSA nanocomposites + laser group. The tumor volume and weight of mices were recorded every 2 days. As shown in Fig. 4b, c, the tumor growth treated with $\mathrm{FeO} /$ $\mathrm{MoS}_{2}$-BSA nanocomposites is obviously slower than those

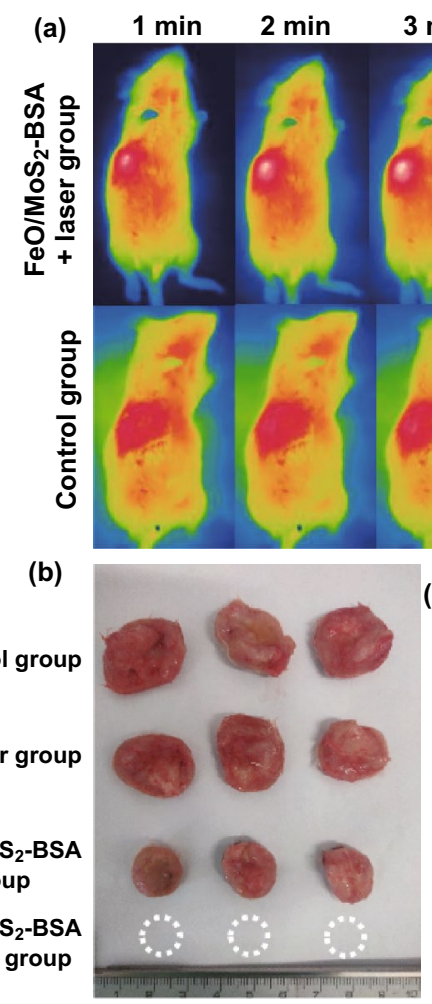

(d)
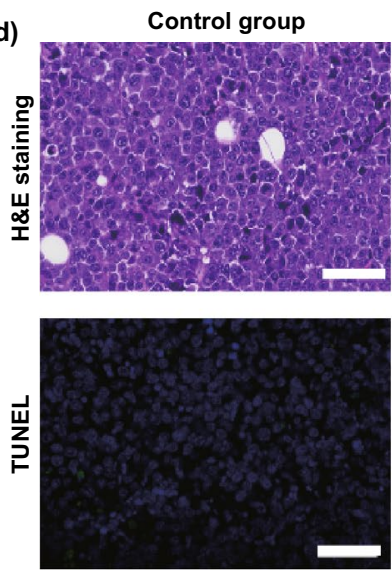

(c)

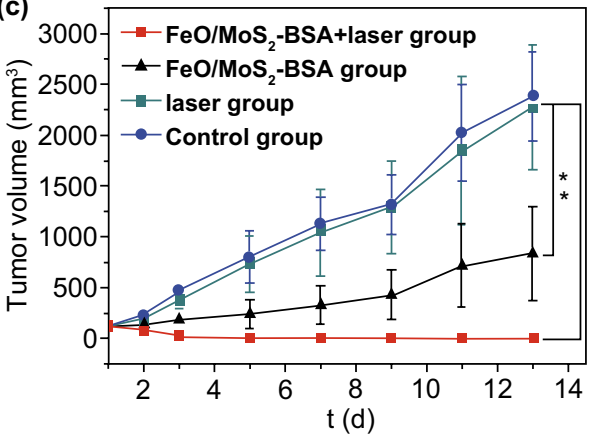

Laser group

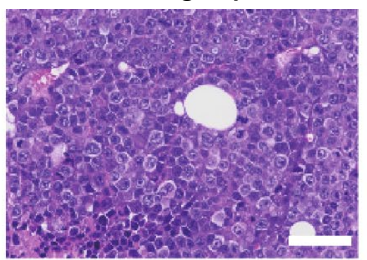

$\mathrm{FeO} / \mathrm{MoS}_{2}$-BSA group
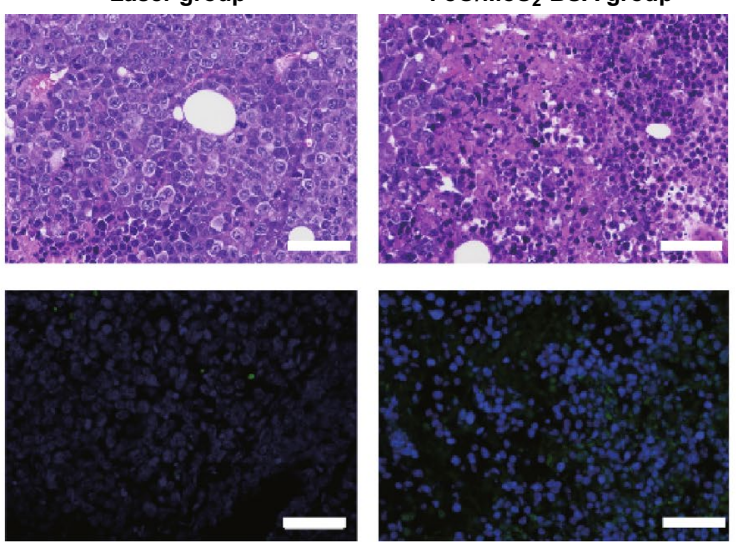

(e)

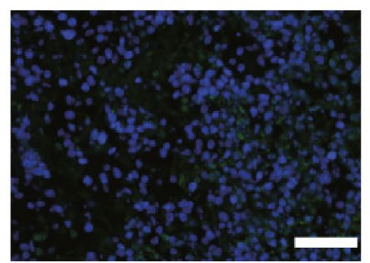

$6 \mathrm{~min} \quad 7 \mathrm{~min} \quad 8 \mathrm{~min} \quad 9 \mathrm{~min} \quad 10 \mathrm{~min}$

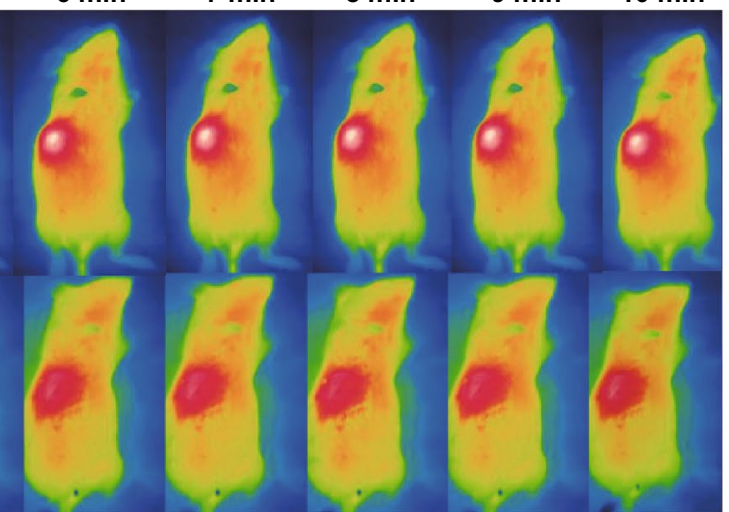

52.0

(e) $36-\mathrm{FeO}_{\mathrm{MoS}}-\mathrm{BSA}+$ laser group
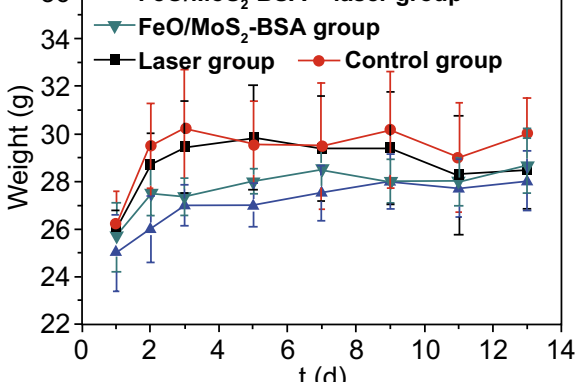

$\mathrm{FeO} / \mathrm{MoS}_{2}-\mathrm{BSA}+$ laser group
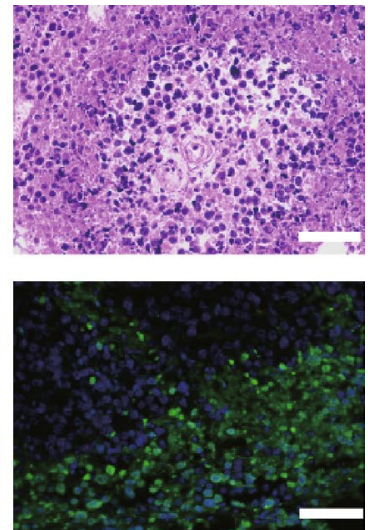

Fig. 4 a IR thermal images of Kunming tumor-bearing mice with tail vein injection of normal saline and $\mathrm{FeO} / \mathrm{MoS}_{2}$-BSA nanocomposites $\left(200 \mu \mathrm{L}, 400 \mu \mathrm{g} \mathrm{mL}^{-1}\right)$ under $1064 \mathrm{~nm}$ laser irradiation $\left(0.75 \mathrm{~W} \mathrm{~cm}^{-2}\right)$ in every minute for $10 \mathrm{~min}$. b Tumor photos harvested from the mices after various treatment at 14th day. $\mathbf{c}$ Tumor volume growth on mice measured after different treatments every 2 days for 2 weeks $(n=6$, $* * P<0.01)$. d H\&E and TUNEL staining of tumor sections harvested from the mice after different treatments at third day (scale bars: $50 \mu \mathrm{m})$. $\mathrm{e}$ Tumor weight growth on mice measured after different treatments every 2 days within 2 weeks 
of control group and laser group, which could be ascribed to the good co-catalytic effect of $\mathrm{MoS}_{2}$ and $\mathrm{FeO}$ for CDT. In contrast, it was found that the tumors treated with $\mathrm{FeO} /$ $\mathrm{MoS}_{2}$-BSA nanocomposites and exposed to $1064 \mathrm{~nm}$ laser were thoroughly ablated on the 5 th day without recurrence within 2 weeks, indicating the excellent anticancer efficacy of synergistic PT-enhanced CDT/PTT. Such result was further proved by the histological analysis of tumor tissues with hematoxylineosin (H\&E) and TdT-mediated dUTP-biotin nick and labeling staining (TUNEL). As shown in Fig. 4d, in contrast with control group and laser group, the tumor tissues of $\mathrm{FeO} / \mathrm{MoS}_{2}-\mathrm{BSA}$ nanocomposites group and $\mathrm{FeO} /$ $\mathrm{MoS}_{2}$-BSA nanocomposites + laser group showed obviously necrosis and apoptosis, implying the treatment efficacy of CDT and PT-enhanced CDT/PTT. In additions, the weight of mice in all groups did not decrease over the duration of treatment, and the H\&E staining results of major organs showed no visible damage compared to the control group, further certifying the low toxicity of $\mathrm{FeO} / \mathrm{MoS}_{2}$-BSA nanocomposites to mice (Figs. $4 \mathrm{e}$ and 5). For further investigating the biocompatibility of $\mathrm{FeO} / \mathrm{MoS}_{2}$ - $\mathrm{BSA}$ nanocomposite, the blood biochemistry assay after intravenous injection with $\mathrm{FeO} / \mathrm{MoS}_{2}$-BSA nanocomposites for $30 \mathrm{~d}$ was conducted. As shown in Fig. S16, there is no remarkable variation of blood index compared with control group, demonstrating good biocompatibility of $\mathrm{FeO} / \mathrm{MoS}_{2}$ - $\mathrm{BSA}$ nanocomposites.

\subsection{Magnetic Resonance Imaging of $\mathrm{FeO} / \mathrm{MoS}_{2}$-BSA in vitro and in vivo}

Owing to the good paramagnetic behavior of $\mathrm{FeO}$ nanoparticles, $\mathrm{FeO} / \mathrm{MoS}_{2}$-BSA nanocomposites are potential $T_{2}$-weighted contrast agents for MRI. As shown in Fig. 6a, the signals of $T_{2}$-weighted MRI are significantly enhanced as the increasing the concentration of $\mathrm{Fe}$, and the transverse relaxivity value $\left(r_{2}\right)$ is calculated as $203.74 \mathrm{mM}^{-1} \mathrm{~s}^{-1}$, which indicates that $\mathrm{FeO} / \mathrm{MoS}_{2}-\mathrm{BSA}$ nanocomposites could act as promising $T_{2}$-weighted MRI contrast agents. In order to further evaluate their feasibility as $T_{2}$-weighted MRI contrast agents in vivo, the MRI of

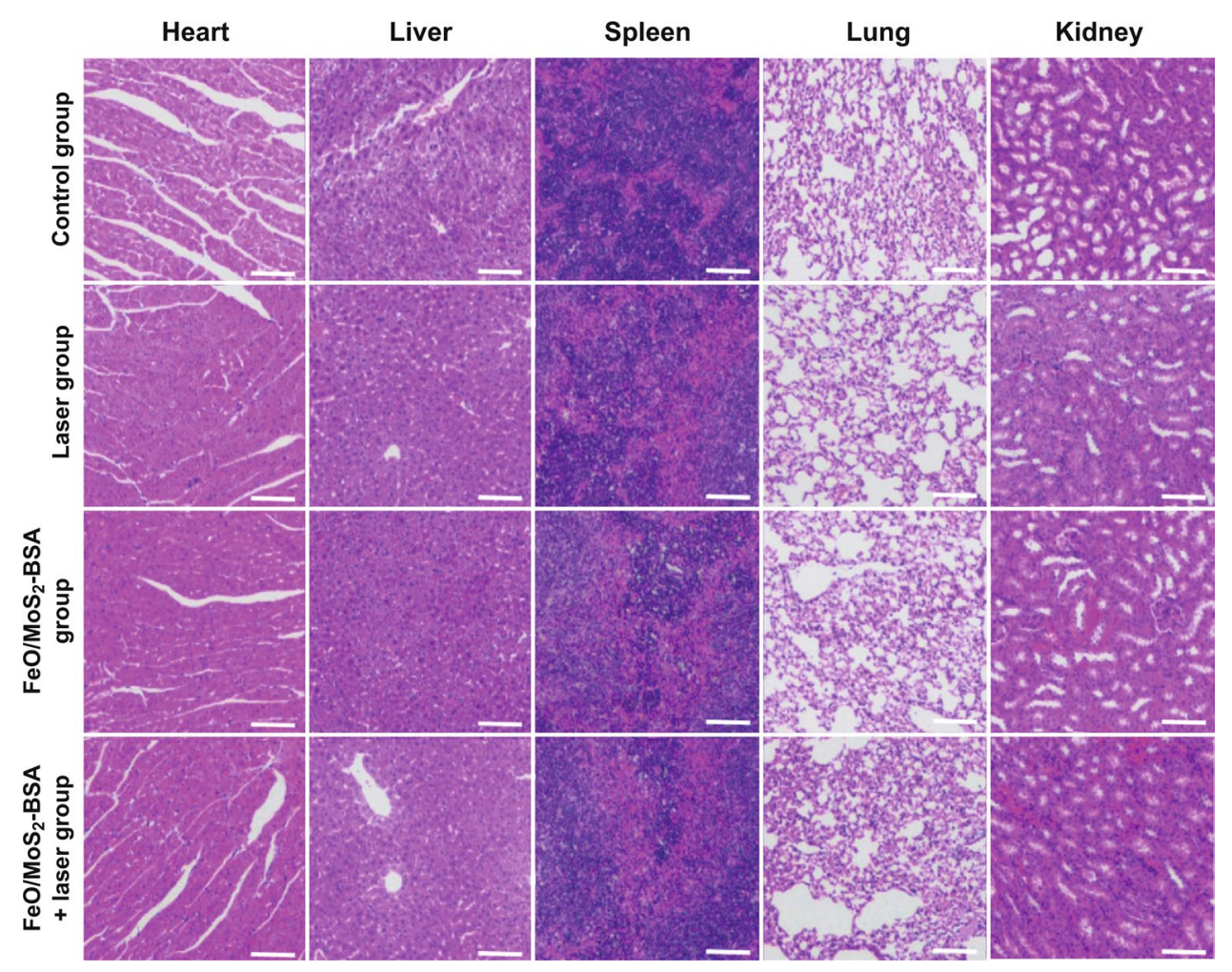

Fig. 5 H\&E staining of organs (heart, liver, spleen, lung, and kidney) harvested from the mices after different treatments at 14th day (scale bars: $100 \mu \mathrm{m})$ 

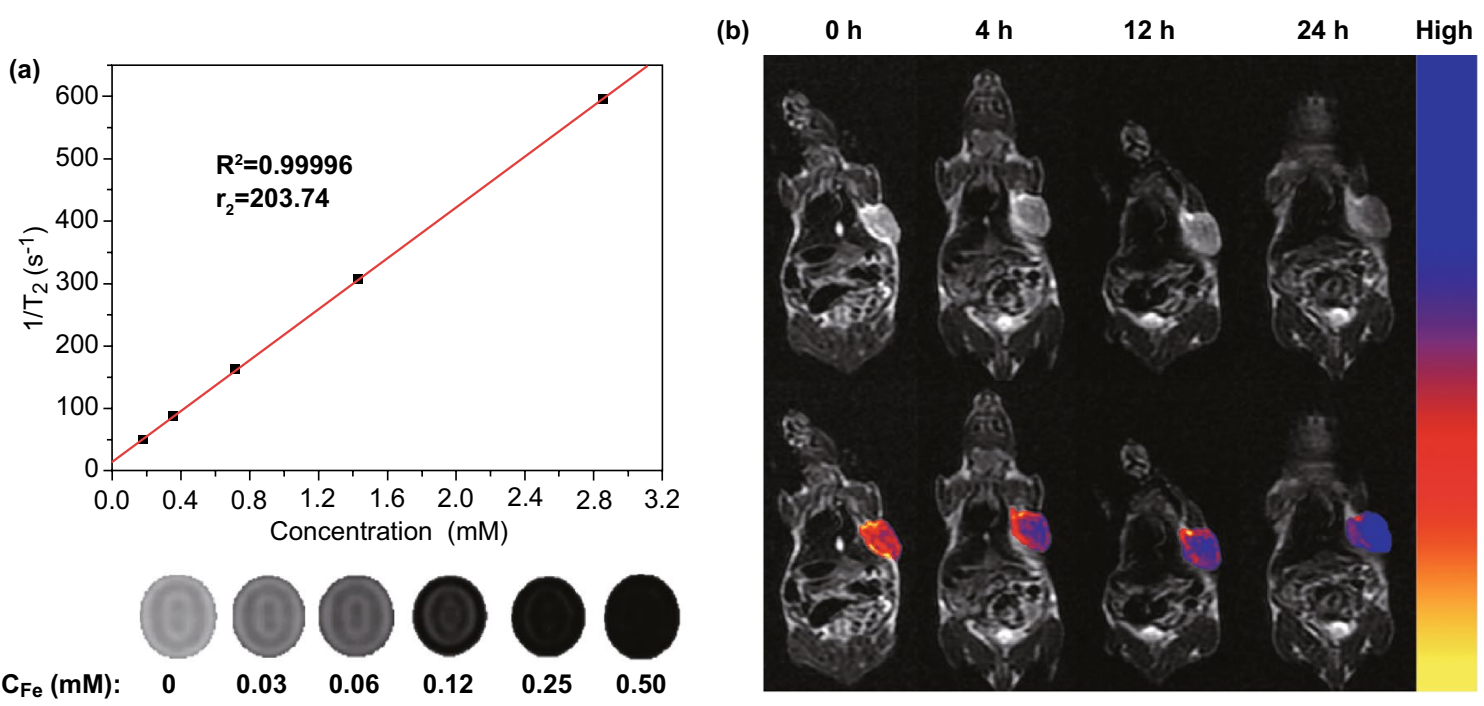

Fig. 6 a $T_{2}$-weighted MR images and $T_{2}$ relaxation rates $\left(r_{2}\right)$ of $\mathrm{FeO} / \mathrm{MoS}_{2}$-BSA nanocomposites. b Magnetic resonance imaging of tumor bearing mice and pseudo color imaging of tumor after tail vein injection for $0,4,12$, and $24 \mathrm{~h}$ in vivo

U14 tumor bearing mice were performed after intravenous injection with $\mathrm{FeO} / \mathrm{MoS}_{2}$-BSA nanocomposites by $3.0 \mathrm{~T}$ human MRI scanner. As shown in Figs. $6 \mathrm{~b}$ and S17, the tumor region is getting darker and lower signal intensity with the prolonging of injection time. The biodistribution of $\mathrm{FeO} / \mathrm{MoS}_{2}$-BSA nanocomposites in vivo further demonstrated the good tumor accumulation of $\mathrm{FeO} / \mathrm{MoS}_{2}$-BSA nanocomposites by enhanced permeability and retention (EPR) effect (Fig. S18). These results reveal that $\mathrm{FeO} /$ $\mathrm{MoS}_{2}$-BSA nanocomposites have good potential for serving as $T_{2}$-weighted MRI contrast agents.

\section{Conclusions}

In summary, the innovative $\mathrm{FeO} / \mathrm{MoS}_{2}$-BSA nanocomposites were constructed to serve as "weapon" for highly efficient synergetic enhanced CDT/PTT of cancer. Not only the FeO nanoparticles and $\mathrm{MoS}_{2}$ nanosheets could generate the $\bullet \mathrm{OH}$ individually as Fenton reagent and nanoenzyme, but also the co-catalytic effect between $\mathrm{Mo}^{4+}$ ions and $\mathrm{Fe}^{3+}$ ions is able to enhance Fenton reaction efficiency for more efficiency CDT. Importantly, $\mathrm{FeO} / \mathrm{MoS}_{2}$-BSA nanocomposites shown excellent photothermal properties under irradiation with $1064 \mathrm{~nm}$ laser, achieving synergetic PT-enhanced CDT and PTT. The outstanding treatment effect has been illustrated both in vitro and in vivo. In addition, the good magnetic property enabled $\mathrm{FeO} / \mathrm{MoS}_{2}$-BSA nanocomposites apply to the promising contrast agents for $T_{2}$-weighted MRI, supplying accurate and clear information for tumor diagnosis. This collaborative strategy based on NIR II light-motivated photothermal effect and co-catalysis may provide a new idea for constructing effective Fenton nanoagents, and boost the development of CDT in future.

Acknowledgements This work was supported by the financial aid from the National Natural Science Foundation of China (Grant Nos. 51502284, 21834007, 21521092, 21590794, and 21673220), the Program of Science and Technology Development Plan of Jilin Province of China (No. 20170101186JC), the Strategic Priority Research Program of the Chinese Academy of Sciences (Grant No. XDB20030300), and the Youth Innovation Promotion Association of Chinese Academy of Sciences (2019232).

Open Access This article is licensed under a Creative Commons Attribution 4.0 International License, which permits use, sharing, adaptation, distribution and reproduction in any medium or format, as long as you give appropriate credit to the original author(s) and the source, provide a link to the Creative Commons licence, and indicate if changes were made. The images or other third party material in this article are included in the article's Creative Commons licence, unless indicated otherwise in a credit line to the material. If material is not included in the article's Creative Commons licence and your intended use is not permitted by statutory regulation or exceeds the permitted use, you will need to obtain permission directly from the copyright holder. To view a copy of this licence, visit http://creativecommons.org/licenses/by/4.0/. 
Electronic supplementary material The online version of this article (https://doi.org/10.1007/s40820-020-00516-z) contains supplementary material, which is available to authorized users.

\section{References}

1. R.L. Siegel, K.D. Miller, A. Jemal, Cancer statistics, 2019. CA Cancer J. Clin. 69(1), 7-34 (2019). https://doi.org/10.3322/ caac. 21551

2. R.L. Siegel, K.D. Miller, A. Jemal, Cancer statistics, 2018. CA Cancer J. Clin. 68(1), 7-30 (2018). https://doi.org/10.3322/ caac. 21442

3. H.J. Bonjer, E. Haglind, I. Jeekel, G. Kazemier, L. Pahlman et al., Laparoscopic surgery versus open surgery for colon cancer: short-term outcomes of a randomised trial. Lancet Oncol. 6(7), 477-484 (2005). https://doi.org/10.1016/s1470 $-2045(05) 70221-7$

4. E. Kapiteijn, C.A.M. Marijnen, I.D. Nagtegaal, H. Putter, W.H. Steup et al., Preoperative radiotherapy combined with total mesorectal excision for resectable rectal cancer. N. Engl. J. Med. 345(9), 638-646 (2001). https://doi. org/10.1056/NEJMoa010580

5. D. Cunningham, W.H. Allum, S.P. Stenning, J.N. Thompson, C.J.H. Van de Velde et al., Perioperative chemotherapy versus surgery alone for resectable gastroesophageal cancer. N. Engl. J. Med. 355(1), 11-20 (2006). https://doi.org/10.1056/ NEJMoa055531

6. H.I. Scher, K. Fizazi, F. Saad, M.-E. Taplin, C.N. Sternberg et al., Increased survival with enzalutamide in prostate cancer after chemotherapy. N. Engl. J. Med. 367(13), 1187-1197 (2012). https://doi.org/10.1056/NEJMoa1207 506

7. Z. Tang, H. Zhang, Y. Liu, D. Ni, H. Zhang et al., Antiferromagnetic pyrite as the tumor microenvironment-mediated nanoplatform for self-enhanced tumor imaging and therapy. Adv. Mater. 29(47), 1701683 (2017). https://doi.org/10.1002/ adma.201701683

8. H. Lin, Y. Chen, J. Shi, Fenton re nanoparticle-triggered in situ catalytic chemical reactions for tumour-specific therapy. Chem. Soc. Rev. 47(6), 1938-1958 (2018). https://doi. org/10.1039/c7cs00471k

9. M.I. Litter, M. Slodowicz, An overview on heterogeneous fenton and photofenton reactions using zerovalent iron materials. J. Adv. Oxid. Technol. 20(1), 160164 (2017). https://doi. org/10.1515/jaots-2016-0164

10. Y. Wang, K. Qi, S. Yu, G. Jia, Z. Cheng et al., Revealing the intrinsic peroxidase-like catalytic mechanism of heterogeneous single-atom Co-MoS 2 . Nano Micro Lett. 11(1), 102 (2019). https://doi.org/10.1007/s40820-019-0324-7

11. C. Yang, M. Zhou, C. He, Y. Gao, S. Li et al., Augmenting intrinsic fenton-like activities of mof-derived catalysts via n-molecule-assisted self-catalyzed carbonization. Nano Micro Lett. 11(1), 87 (2019). https://doi.org/10.1007/s4082 0-019-0319-4
12. M. Huo, L. Wang, Y. Chen, J. Shi, Tumor-selective catalytic nanomedicine by nanocatalyst delivery. Nat. Commun. 8(1), 357 (2017). https://doi.org/10.1038/s41467-017-00424-8

13. W. Wang, Y. Jin, Z. Xu, X. Liu, S.Z. Bajwa, W.S. Khan, H. Yu, Stimuli-activatable nanomedicines for chemodynamic therapy of cancer. Wiley Interdiscip. Rev. Nanomed. Nanobiotechnol. 12(4), e1614 (2020). https://doi.org/10.1002/wnan.1614

14. Z. Tang, Y. Liu, M. He, W. Bu, Chemodynamic therapy: Tumour microenvironment-mediated fenton and fenton-like reactions. Angew. Chem. Int. Ed. 58(4), 946-956 (2019). https ://doi.org/10.1002/anie.201805664

15. S. Wang, G. Yu, Z. Wang, O. Jacobson, L.S. Lin et al., Enhanced antitumor efficacy by a cascade of reactive oxygen species generation and drug release. Angew. Chem. Int. Ed. 58(41), 14758-14763 (2019). https://doi.org/10.1002/ anie. 201908997

16. Y. Liu, J. Wu, Y. Jin, W. Zhen, Y. Wang et al., Copper (i) phosphide nanocrystals for in situ self-generation magnetic resonance imaging-guided photothermal-enhanced chemodynamic synergetic therapy resisting deep-seated tumor. Adv. Funct. Mater. (2019). https://doi.org/10.1002/adfm.201904678

17. Y. Liu, W. Zhen, Y. Wang, J. Liu, L. Jin et al., One-dimensional $\mathrm{Fe}_{2} \mathrm{P}$ acts as a fenton agent in response to NIR ii light and ultrasound for deep tumor synergetic theranostics. Angew. Chem. Int. Ed. 58(8), 2407-2412 (2019). https://doi. org/10.1002/anie.201813702

18. L. Xu, J. Wang, Magnetic nanoscaled $\mathrm{Fe}_{3} \mathrm{O}_{4} / \mathrm{CeO}_{2}$ composite as an efficient fenton-like heterogeneous catalyst for degradation of 4-chlorophenol. Environ. Sci. Technol. 46(18), 1014510153 (2012). https://doi.org/10.1021/es300303f

19. M. Xing, W. Xu, C. Dong, Y. Bai, J. Zeng et al., Metal sulfides as excellent co-catalysts for $\mathrm{H}_{2} \mathrm{O}_{2}$ decomposition in advanced oxidation processes. Chem 4, 1359-1372 (2018). https://doi. org/10.1016/j.chempr.2018.03.002

20. X. Nie, L. Xia, H.L. Wang, G. Chen, B. Wu et al., Photothermal therapy nanomaterials boosting transformation of $\mathrm{Fe}$ (iii) into Fe(ii) in tumor cells for highly improving chemodynamic therapy. ACS Appl. Mater. Interfaces 11(35), 31735-31742 (2019). https://doi.org/10.1021/acsami.9b11291

21. L. Zhang, S.S. Wan, C.X. Li, L. Xu, H. Cheng, X.Z. Zhang, An adenosine triphosphate-responsive autocatalytic fenton nanoparticle for tumor ablation with self-supplied $\mathrm{H}_{2} \mathrm{O}_{2}$ and acceleration of $\mathrm{Fe}(\mathrm{iii}) / \mathrm{Fe}$ (ii) conversion. Nano Lett. 18(12), 7609-7618 (2018). https://doi.org/10.1021/acs.nanolett.8b031 78

22. T. Liu, S. Shi, C. Liang, S. Shen, L. Cheng et al., Iron oxide decorated $\mathrm{MoS}_{2}$ nanosheets with double pegylation for chelator-free radio labeling and multimodal imaging guided photothermal therapy. ACS Nano 9(1), 950-960 (2015). https://doi. org/10.1021/nn506757x

23. J. Yu, W. Yin, X. Zheng, G. Tian, X. Zhang et al., Smart $\mathrm{MoS}_{2} /$ $\mathrm{Fe}_{3} \mathrm{O}_{4}$ nanotheranostic for magnetically targeted photothermal therapy guided by magnetic resonance/photoacoustic imaging. Theranostics 5(9), 931-945 (2015). https://doi.org/10.7150/ thno. 11802 
24. S.S. Chou, B. Kaehr, J. Kim, B.M. Foley, M. De et al., Chemically exfoliated $\mathrm{MoS}_{2}$ as near-infrared photothermal agents. Angew. Chem. Int. Ed. 52(15), 4160-4164 (2013). https://doi. org/10.1002/anie.201209229

25. C. Liu, J. Chen, Y. Zhu, X. Gong, R. Zheng et al., Highly sensitive $\mathrm{MoS}_{2}$-indocyanine green hybrid for photoacoustic imaging of orthotopic brain glioma at deep site. Nano-Micro Lett. 10(3), 48 (2018). https://doi.org/10.1007/s40820-018-0202-8

26. W. Yin, J. Yu, F. Lv, L. Yan, L.R. Zheng, Z. Gu, Y. Zhao, Functionalized nano- $\mathrm{MoS}_{2}$ with peroxidase catalytic and nearinfrared photothermal activities for safe and synergetic wound antibacterial applications. ACS Nano 10(12), 11000-11011 (2016). https://doi.org/10.1021/acsnano.6b05810

27. F. Cao, L. Zhang, H. Wang, Y. You, Y. Wang et al., Defectrich adhesive nanozymes as efficient antibiotics for enhanced bacterial inhibition. Angew. Chem. Int. Ed. (2019). https://doi. org/10.1002/anie.201908289

28. Z. Wang, Y. Ju, Z. Ali, H. Yin, F. Sheng et al., Near-infrared light and tumor microenvironment dual responsive sizeswitchable nanocapsules for multimodal tumor theranostics. Nat. Commun. 10(1), 4418 (2019). https://doi.org/10.1038/ s41467-019-12142-4

29. S. Aktaş, S.C. Thornton, C. Binns, L. Lari, A. Pratt, R. Kröger, M.A. Horsfield, Control of gas phase nanoparticle shape and its effect on MRI relaxivity. Mater. Res. Express 2(3), 035002 (2015). https://doi.org/10.1088/2053-1591/2/3/035002

30. B. Tang, W.-L. Li, Y. Chang, B. Yuan, Y. Wu et al., A supramolecular radical dimer: High-efficiency NIR-ii photothermal conversion and therapy. Angew. Chem. Int. Ed. (2019). https ://doi.org/10.1002/anie.201910257

31. X. Wu, Y. Suo, H. Shi, R. Liu, F. Wu et al., Deep-tissue photothermal therapy using laser illumination at NIR-iia window. Nano-Micro Lett. 12(1), 38 (2020). https://doi.org/10.1007/ s40820-020-0378-6

32. J.-L. Chen, H. Zhang, X.-Q. Huang, H.-Y. Wan, J. Li et al., Antiangiogenesis-combined photothermal therapy in the second near-infrared window at laser powers below the skin tolerance threshold. Nano Micro Lett. 11(1), 93 (2019). https://doi. org/10.1007/s40820-019-0327-4

33. W. Feng, X. Han, R. Wang, X. Gao, P. Hu et al., Nanocatalysts-augmented and photothermal-enhanced tumor-specific sequential nanocatalytic therapy in both $N I R$-i and $N I R$-ii biowindows. Adv. Mater. 31(5), e1805919 (2019). https://doi. org/10.1002/adma.201805919

34. W.P. Li, C.H. Su, Y.C. Chang, Y.J. Lin, C.S. Yeh, Ultrasoundinduced reactive oxygen species mediated therapy and imaging using a fenton reaction activable polymersome. ACS Nano 10(2), 2017-2027 (2016). https://doi.org/10.1021/acsna no. 5 b06175

35. A. Dong, X. Ye, J. Chen, Y. Kang, T. Gordon, J.M. Kikkawa, C.B. Murray, A generalized ligand-exchange strategy enabling sequential surface functionalization of colloidal nanocrystals. J. Am. Chem. Soc. 133(4), 998-1006 (2011). https://doi. org/10.1021/ja108948z 